\title{
PHOTOCHEMICAL PARTICULATE FORMATION IN CYCLOHEXENE-NITROGEN DIOXIDE-AIR MIXTURES
}

\author{
ChI-Hung Shen and George S. Springer \\ Department of Mechanical Engineering. The University of Michigan, \\ Ann Arbor, Michigan 48109, U.S.A.
}

(Received 11 June 1977)

\begin{abstract}
Experiments were performed investigating the formation of condensation nuclei (particles smaller than $0.1 \mu \mathrm{m}$ ) and light scattering particles (particles larger than $0.3 \mu \mathrm{m}$ ) in cyclohexene-nitrogen dioxide-air mixtures flowing inside a $9 \mathrm{~m}$ long and $15 \mathrm{~cm}$ i.d. Pyrex tube irradiated by u.v. fluorescent lamps. The initial cyclohexene concentration in the mixture was varied from $0.5-50 \mathrm{ppm}$ and the initial nitrogen dioxide concentration from $0.6-10 \mathrm{ppm}$. The number $\left(\mathrm{cm}^{-3}\right)$ of both the nuclei and the particles were measured. The data provide the number of nuclei and particles formed in the mixture. On the basis of the data obtained, dimensionless parameters were established for correlating the numbers of nuclei and particles generated by photochemical reactions.
\end{abstract}

\section{INTRODUCTION}

Photochemical formation of particulates has been investigated widely (e.g. see Shen and Springer, 1975). In most previous work the emphasis was on determining the influence of the type of hydrocarbon on the physical characteristics of the particulate matter. The effects of the initial concentrations of the gaseous reactants on particulate formation have not yet been studied in detail. The major objectives of this investigation were, therefore, to assess the effects of nitrogen dioxide and hydrocarbon concentrations on the number of particulates generated in photochemical reactions, and to examine the relationship between the number of particulates and the amount of ozone in the mixture. To accomplish these objectives the number $\left(\mathrm{cm}^{-3}\right)$ of the particulates formed in irradiated mixtures of cyclohexene-nitrogen dioxide-air were measured. Cyclohexene was selected for this study because of the many different types of hydrocarbons tested in the past this was found to produce the most particulates (Groblicki and Nebel, 1971; Prager et al., 1960; Renzetti and Doyle, 1960; Steven- son et al., 1965). The use of cyclohexene also facilitated comparisons between the formation of ozone and particulate matter, the results for ozone having been given in Shen et al. (1977).

\section{EXPERIMENTAL}

The apparatus and the experimental procedures were essentially the same as those given by Shen and Springer (1976) and by Shen et al. (1977) and, therefore, they are not described here in detail. Only a brief summary is provided to facilitate the understanding of the results.

The photochemical reactions were generated in a $9 \mathrm{~m}$ long, $15.2 \mathrm{~cm}$ i.d. Pyrex tube arranged horizontally in a straight line ("tunnel" in Fig. 1). Twelve openings were made on the top of the tube for inserting sampling probes. The first opening was $23 \mathrm{~cm}$ from the entrance of the tunnel. The distance between any two successive openings was $76 \mathrm{~cm}$. Samples were taken at each sampling location. The particles were examined in two different categories. The first category consisted of those particles whose diameters were between $2 \mathrm{~nm}$ and $0.1 \mu \mathrm{m}$. These particles were designated as condensation nuclei and their number was measured by a condensation nuclei counter (Gardner Associates "Small Particle Detector"). In the sccond catcgory were all those particles whose diameters were larger than

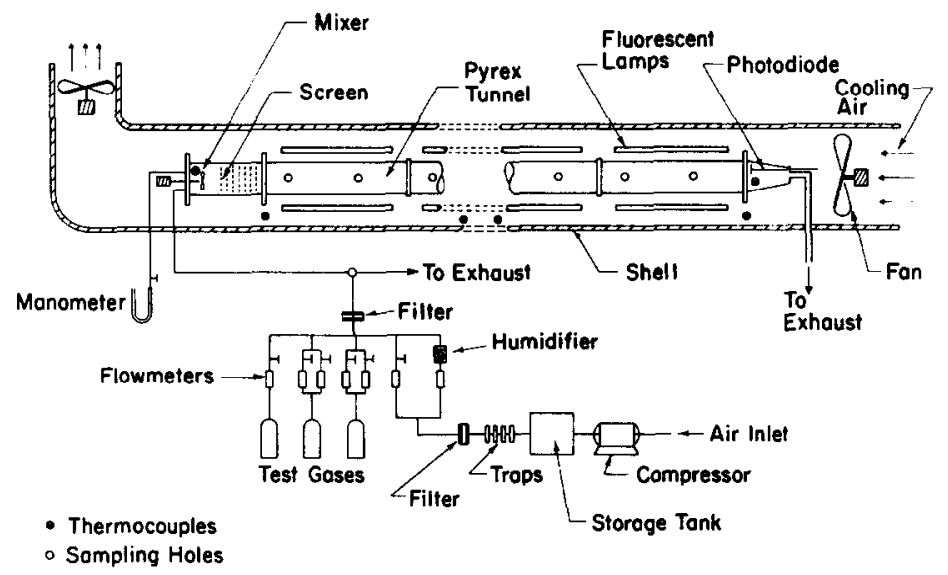

Fig. 1. Schematic diagram of experimental apparatus. 
$0.3 \mu \mathrm{m}$. These were designated as 'particles' and their number was measured by a Model 225 Royco Particle Counter.

A detailed estimate was made of the magnitude of errors (Shen and Springer, 1975); the maximum error in the nuclei measurements was about $\pm 40 \%$ and in the particle measurements it was about $\pm 30 \%$. To minimize the error caused by statistical fluctuations, every measurement was repeated at least three times. The data points shown are the averages of the measured values.

The ozone concentration along the tunnel was also measured during the tests with a Thermo Electron Corporation Model 12A Chemiluminescent Analyzer (Shen et al., 1977).

At the start of each series of tests the ultraviolet lamps were turned on and $50 \%$ relative humidity air (without any of the test gases) was fed through the tunnel continuously until the nuclei and particle counters (as well as the ozone detector) indicated zero readings at every sampling station. The required gas-air mixture was then introduced into the tunnel. The nuclei and particle concentrations were measured at different sampling stations after their values stabilized along the entire length of the tunnel.

In the subsequent discussions the specified test gas concentration refers to the amount of test gas in the air-gas mixture at the entrance of the tunnel, i.e. before the mixture was exposed to the ultraviolet light. This concentration is denoted by the subscript $a$.

The number of particulates formed in a cyclohexenenitrogen dioxide-air mixture depend on (a) the initial concentration of cyclohexene, (b) the initial concentration of nitrogen dioxide, (c) the relative humidity, (d) the u.v. intensity, and (e) the length of time the mixture is irradiated. In this study the major interest was in the first two of these effects (points $a$ and $b$ ). Therefore, in most of the tests the relative humidity was maintained at $50 \%$ and the light intensity was kept constant $\left(k_{1}=0.0063 \mathrm{~s}^{-1}\right)$, the flow rate was maintained at $46 \mathrm{~cm}^{3} \mathrm{~s}^{-1}$, giving an average residence time of approximately 1 hour.

Five concentrations of cyclohexene $(0.5,1,2,3$, and 5 $\mathrm{ppm})$ and five concentrations of nitrogen dioxide $(0.6,1$, 2,3 , and $5 \mathrm{ppm}$ ) were employed in the tests providing twenty-five different mixture composition combinations. These measurements were performed at $50 \%$ relative humi- dity. Some measurements were also performed at 100\% relative humidity at mixture compositions of $1,2,3,5$. and $10 \mathrm{ppm}$ cyclohexene and $1 \mathrm{ppm}$ nitrogen dioxide.

\section{RESLLTS AND DISCUSSION}

The nuclei and the particle contents in the tunnel are given in Fig. 2 for a typical set of cyclohexene and nitrogen dioxide concentrations. For other concentrations of nitrogen dioxide and cyclohexene the nuclei and the particle contents along the tunnel exhibited similar trends. The number of nuclei and particles changed along the tunnel due to coagulation, diffusion, and deposition. However, the number of nuclei and particles remained reasonably constant beyond the third sampling station, suggesting that beyond this point the formation and depletion of nuclei and particles proceeded at nearly the same rates. Here we were not concerned with the details of the complex processes governing the rate of growth of particulates along the tunnel, but were only interested in (a) the dependence of the number of nuclei and particles on the initial concentrations of cyclohexene and nitrogen dioxide and (b) the relationship between the number of nuclei, the number of particles and the ozone concentration in the mixture. For the purposes of these objectives, it was adequate to characterize the nuclei and particle contents each by their maximum concentrations in the tunnel, i.e. by the maximum number of nuclei and particles generated for each combination of nitrogen dioxide and cyclohexene concentrations. Therefore, in all subsequent discussions the term 'number' is used to denote the maximum values in the tumel. These were determined by plotting all the data in a manner similar to Fig. 2 and by estimating the maxima from these plots.
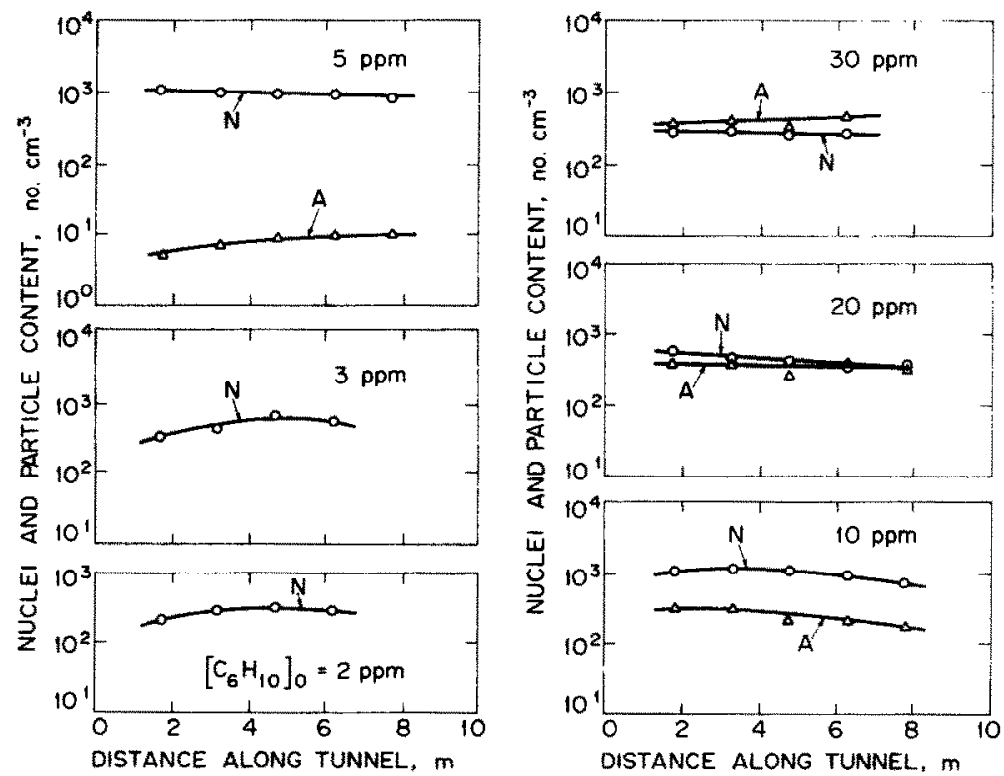

Fig. 2. Typical variations of nuclei and particle contents along the tunnel is cyclohexene-nitrogen dioxide-air mixtures. Initial nitrogen dioxide concentration: 3 ppm. Relative humidity: $50 \%$. 

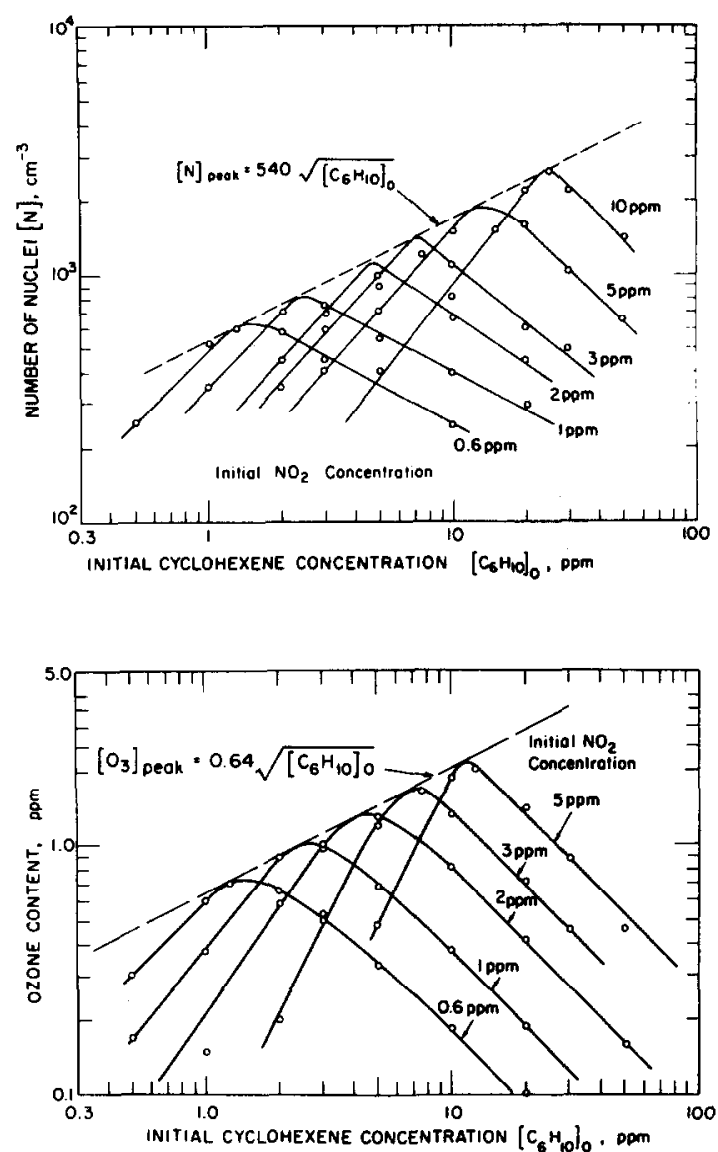

Fig. 3. Cyclohexene-nitrogen dioxide-air mixtures, (a) nuclei content, (b) ozone concentrations (Shen et al., 1977). Relative humidity: $50 \%$ Light intensity $k_{1}=0.0063 \mathrm{~s}^{-1}$.

The number of nuclei $[\mathrm{N}]$ produced for different concentrations of cyclohexene and nitrogen dioxide is given in Fig. 3. In order to explore the relationship between the production of ozone and the production of nuclei in the mixture, the maximum amount of ozone $\left[\mathrm{O}_{3}\right]_{\max }$ produced in the tunnel for different concentrations of cyclohexene and nitrogen dioxide is also included in Fig. 3 (Shen et al., 1976). It must be noted that the maximum numbers of nuclei and particles, as well as the maximum amount of ozone, depend only on the initial mixture composition and on the light intensity, and are independent of the irradiation time (provided that the light remains on long enough to reach these maxima). However, the times required to reach these maxima are different for different initial cyclohexene and nitrogen dioxide concentrations.

The variation in the nuclei content with the nitrogen dioxide and the cyclohexene concentrations is remarkably similar to the variation of the ozone content with the concentrations of nitrogen dioxide and cyclohexene. For example, as in the case of ozone, for a given nitrogen dioxide concentration the number of nuclei first increased with the cyclohexene concentration, reached a peak, and then decreased with a further increase in the cyclohexene concen- tration. Moreover, for a given nitrogen dioxide concentration the amounts of ozone and nuclei reached their respective peaks at approximately the same cyclohexene concentration. For example, for a $2 \mathrm{ppm}$ nitrogen dioxide concentration the number of nuclei peaked at $\left[\mathrm{C}_{6} \mathrm{H}_{10}\right]_{0}=4.4 \mathrm{ppm}$. For this same $\mathrm{NO}_{2}$ concentration the ozone content reached its peak at about $\left[\mathrm{C}_{6} \mathrm{H}_{10}\right]_{0}=4.6 \mathrm{ppm}$.

The similarity between the nuclei and ozone contents becomes evident further, if the data in Fig. 3 are replotted in dimensionless form. It was shown by Shen et al. (1977) that, for a mixture containing only one type of hydrocarbon, the ozone concentration nondimensionalized with respect to $\sqrt{\left(k_{1} / k_{3}\right)\left[\mathrm{NO}_{2}\right]_{0}}$ depends only on a function of the ratio of the hydrocarbon concentration to the nitrogen dioxide concentration, i.e.

$$
\frac{\left[\mathrm{O}_{3}\right]_{\max }}{\sqrt{\left(k_{1} / k_{3}\right)\left[\mathrm{NO}_{2}\right]_{0}}}=g\left(\frac{[\mathrm{HC}]_{0}}{\left[\mathrm{NO}_{2}\right]_{0}}\right)
$$

where $k_{1}$ and $k_{3}$ are the rate constants for the reactions $\mathrm{NO}_{2}+h v \rightarrow \mathrm{NO}+\mathrm{O}$ and $\mathrm{O}_{3}+\mathrm{NO} \rightarrow$ $\mathrm{NO}_{2}+\mathrm{O}_{2}$, respectively $\left(k_{3}=0.425 \mathrm{ppm}^{-1} \mathrm{~s}^{-1}\right)$. The data for ozone, nondimensionalized according to eq. (1), are given in Fig. 4.

One expects the ozone and nuclei formations to be related. Therefore, analogous to eq. (1) we now write arbitrarily

$$
\frac{[\mathrm{N}]}{2.46 \times 10^{13} \sqrt{\left(k_{1} / k_{3}\right)\left[\mathrm{NO}_{2}\right]_{0}}}=f\left(\frac{[\mathrm{HC}]_{0}}{\left[\mathrm{NO}_{2}\right]_{0}}\right)
$$

$[N]$ is the number of nuclei per $\mathrm{cm}^{3}$. Since the unit of $\sqrt{\left(k_{1} / k_{3}\right)\left[\mathrm{NO}_{2}\right]_{0}}$ is ppm, the numerical constant $2.46 \times 10^{13}$ no. of molecules $\mathrm{cm}^{-3} \mathrm{ppm}^{-1}$ at 1 atmosphere and $298 \mathrm{~K}$ is introduced to render the left hand side of this equation dimensionless. It is emphasized that the symbols $g$ and $f$ represent functional relationships which must be determined from data.

The form of eq. (2) is arbitrary and its validity must be evaluated. Equation (2) is appropriate if on a $[\mathrm{N}] /$ $2.46 \times 10^{13} \sqrt{\left(k_{1} / k_{3}\right)\left[\mathrm{NO}_{2}\right]_{0}}$ versus $[\mathrm{HC}]_{0} /\left[\mathrm{NO}_{2}\right]_{0}$ plot all data fall on a common curve. Such a plot is presented in Fig. 4 which shows that, within the errors of the measurements, all the data collapse onto one curve. This lends support to the validity of eq. (2).

A comparison between the nondimensional plots for ozone and nuclei (Figs. 4a and 4b) shows that both the dimensionless ozone concentration and the dimensionless number of nuclci reach their peak values at the same ratio of cyclohexene to nitrogen dioxide concentration $\left(\left[\mathrm{C}_{6} \mathrm{H}_{10}\right]_{0} /\left[\mathrm{NO}_{2}\right]_{0}=2.4\right)$.

We wish to determine now the highest possible number of nuclei $[\mathrm{N}]_{\text {peak }}$ which can be produced either for a given initial cyclohexene concentration, or for a given initial nitrogen dioxide concentration. To accomplish this we denote by $R$ the concentration ratio at which the dimensionless nuclei count has its peak and by $S$ the number of nuclei at this ratio. 

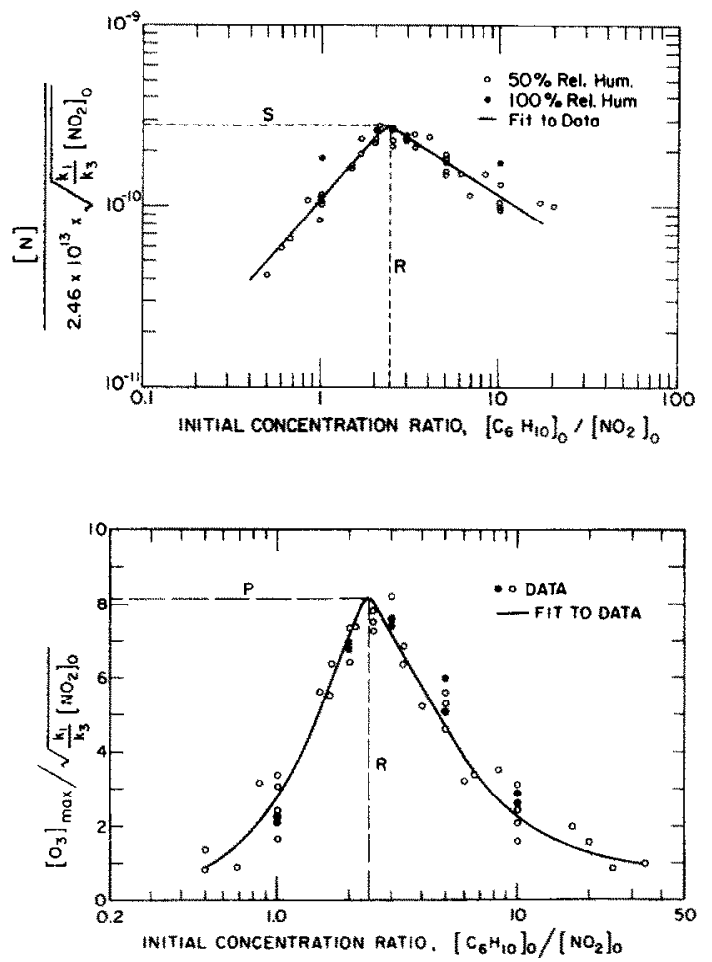

Fig. 4. Cyclohexene-nitrogen dioxide-air mixtures. (a) nuclei content. (b) ozone concentration (Shen et al., 1977). Light intensity $k_{1}=0.0063 \mathrm{~s}^{-1}$

Thus, at $[N]=[N]_{\text {peak }}$ we write

$$
R=\frac{\left[\mathrm{C}_{6} \mathrm{H}_{10}\right]_{0}}{\left[\mathrm{NO}_{2}\right]_{0}}
$$

and

$$
S=\frac{[\mathrm{N}]_{\text {peak }}}{2.46 \times 10^{13} \sqrt{\left(k_{1} / k_{3}\right)\left[\mathrm{NO}_{2}\right]_{0}}}
$$

The above empirical expressions may be rearranged in the form

$[\mathrm{N}]_{\text {peak }}=2.46 \times 10^{13} \mathrm{~S} \sqrt{\frac{k_{1}}{k_{3}}\left[\mathrm{NO}_{2}\right]_{0}} \mathrm{~cm}^{-3}$

$[\mathrm{N}]_{\text {peak }}=2.46 \times 10^{13} \frac{S}{\sqrt{R}} \sqrt{\frac{k_{1}}{k_{3}}\left[\mathrm{C}_{6} \mathrm{H}_{10}\right]_{0}} \mathrm{~cm}^{-3}$.

For cyclohexene Fig. 4 gives the values of $R$ and $S$ as 2.4 and $2.8 \times 10^{-10}$. Correspondingly, eqs. (4) and (5) may be expressed as

$[\mathrm{N}]_{\text {peak }}=835 \sqrt{\left[\mathrm{NO}_{2}\right]_{0}} \mathrm{~cm}^{-3}$

and

$[N]_{\text {peak }}=540 \sqrt{\left[\mathrm{C}_{6} \mathrm{H}_{10}\right]_{0}} \mathrm{~cm}^{-3}$

where $\left[\mathrm{C}_{6} \mathrm{H}_{10}\right]_{0}$ and $\left[\mathrm{NO}_{2}\right]_{0}$ are in ppm. Equations (6) and (7) show that the peak number of nuclei varies directly with the square root of both the cyclohexene concentration and the nitrogen dioxide concentration.
This result is again similar to the one found for ozone. As was shown by Shen et al. (1977) the peak ozone concentration also varies with $\sqrt{\left[\mathrm{C}_{6} \mathrm{H}_{10}\right]_{0}}$ and $\sqrt{\left[\mathrm{NO}_{2}\right]_{0}}$.

It would be of interest now to assess (a) whether or not eqs. (4) and (5) could be applied to other types of hydrocarbons besides cyclohexene, and (b) the values of $R$ and $S$ for different types of hydrocarbons. However, to evaluate the general validity of these equations and to determine $R$ and $S$ data such as reported here but obtained with different types of hydrocarbons would be needed. Unfortunately, such data are unavailable. There appears to be only one nuclei measurement which can be compared directly with the present results. Stevenson et al. (1965) performed experiments in a $0.125 \mathrm{~m}^{3}$ Pyrex tube irradiated by fluorescent lamps, and reported that for a mixture containing $2 \mathrm{ppm}$ of nitrogen dioxide and $3.5 \mathrm{ppm}$ of cyclohexene the number of nuclei produced was about $700 \mathrm{~cm}^{-3}$. For the corresponding mixture composition the present data indicate a nuclei count of $800 \mathrm{~cm}^{-3}$ (Fig. 3) which is in good agreement with the value obtained by Stevenson et al.

The number of light scattering particles [A] as a function of the cyclohexene and nitrogen dioxide concentrations is shown in Fig. 5. For a given nitrogen dioxide concentration the particle content ([A] in number $\mathrm{cm}^{-3}$ ) at first increased sharply with increasing concentrations of cyclohexene. At about 400 particles $\mathrm{cm}^{-3}$ the particle content gradually leveled off with further increase in the cyclohexene concentration. Figure 5 does not provide much information on the relationship between the number of particles formed and the initial concentration of nitrogen dioxide and cyclohexene. However, when the particle content is replotted in terms of the dimensionless parameters $[\mathrm{A}] / 2.46 \times 10^{13} \sqrt{\left(k_{1} / k_{3}\right)\left[\mathrm{NO}_{2}\right]_{0}}$ and $\left[\mathrm{C}_{6} \mathrm{H}_{10}\right]_{0} /\left[\mathrm{NO}_{2}\right]_{0}$ the data points all seem to collapse onto one common curve (Fig. 6) just as in the case of ozone and nuclei. It is of interest to note that the particle content becomes appreciable only when the concentration ratio $\left(\left[\mathrm{C}_{6} \mathrm{H}_{10}\right]_{0} /\left[\mathrm{NO}_{2}\right]_{0}\right.$ is larger than about 2.4 , the same value at which the amounts of nuclei and ozone reached their peaks (Fig. 4). When the ratio is below 2.4 only about 50 particles $\mathrm{cm}^{-3}$ are generated in the mixture. This is a small number compared to the nearly 600 aerosols $\mathrm{cm}^{-3}$ generated when the concentration ratio is $\sim 10$.

Direct comparisons between the present and existing particle data are not possible because in most previous investigations the number count of the particles was not reported. In past measurements the light scattering method was generally employed which provided the amount of light scattered by the particles but did not yield directly the number of particles per unit volume. One exception was the test by Renzetti and Doyle (1960) who performed experiments in a $0.05 \mathrm{~m}^{3}$ Pyrex flask irradiated by mercury arc lamps. They reported the number of particles produced to be $290 \mathrm{~cm}^{-3}$ in a mixture containing $1 \mathrm{ppm}$ 


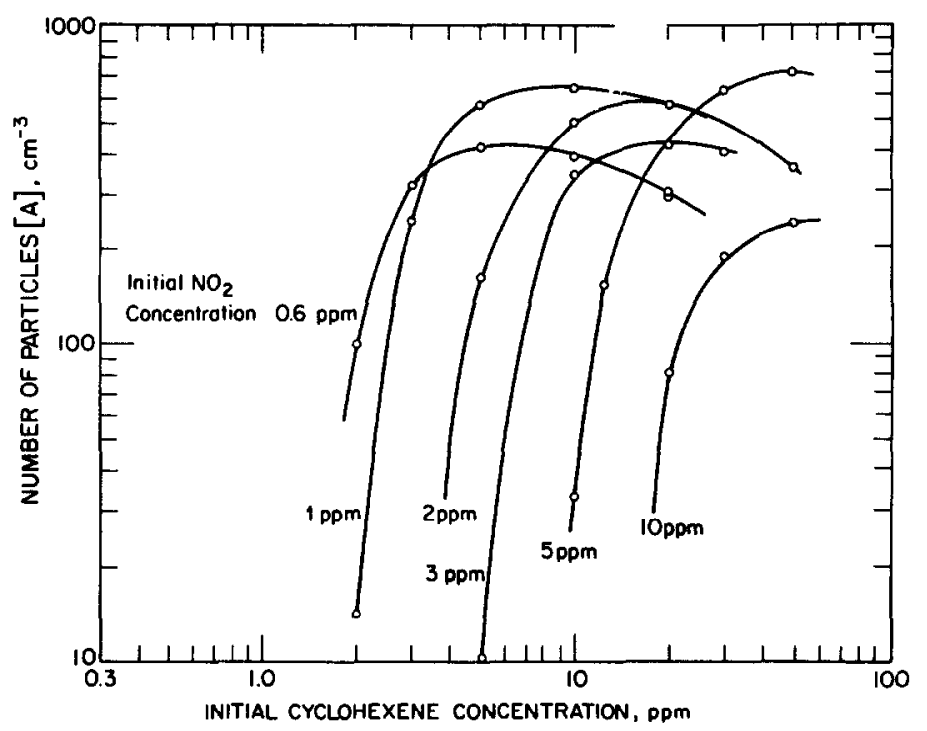

Fig. 5. Particle content in cyclohexene-nitrogen dioxide-air mixtures. Relative humidity: $50 \%$. Light intensity $k_{1}=0.0063 \mathrm{~s}^{-1}$

nitric oxide and $3 \mathrm{ppm}$ cyclohexene at a relative humidity of $50 \%$. For the same condition the present measurements give the number of particles as $250 \mathrm{~cm}^{-3}$ (Fig. 5), which is in good agreement with Renzetti and Doyle's data.

Although quantitative comparisons between the present data and the data obtained by light scattering methods cannot be made, qualitative comparisons are possible because the amount of light scattered is proportional to the number of particles in the mixture. Measurements of light scattering in hydrocarbonnitrogen oxides-air mixtures were reported for forty different hydrocarbons by Groblicki and Nebel (1971), Prager et al. (1960), Renzetti and Doyle (1960), and Stevenson et al. (1965). However, in each

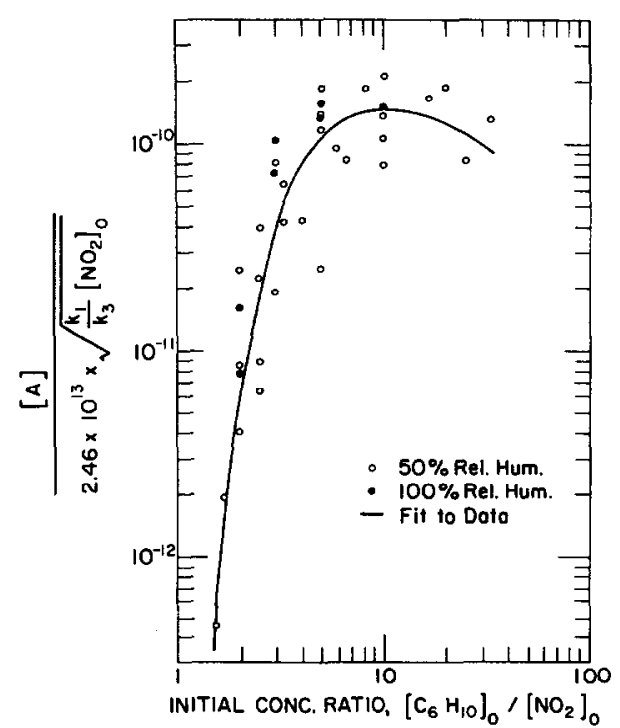

Fig. 6. Normalized particle content in cyclohexenenitrogen dioxide-air mixtures. Light intensity $k_{1}=$ $0.0063 \mathrm{~s}^{-1}$. measurement only one set of hydrocarbon and nitrogen oxides concentration was tested. Hence, a particle light scattering versus concentration ratio curve could not be obtained for any of these hydrocarbons, with the exception of cyclohexene for which light scattering was measured by all of the aforementioned investigators. For cyclohexene the amount of light scattered at different concentration ratios is plotted in Fig. 7. The figures showing the amount of light scattered (Fig. 7) and the actual number count (Fig. 6) exhibit certain common features. First, both the particle light scattering and the particle number count indicate that when the initial concentration ratio is increased from 2 to 5 the amount of particle produced is increased by a factor of ten (i.e. the particle content

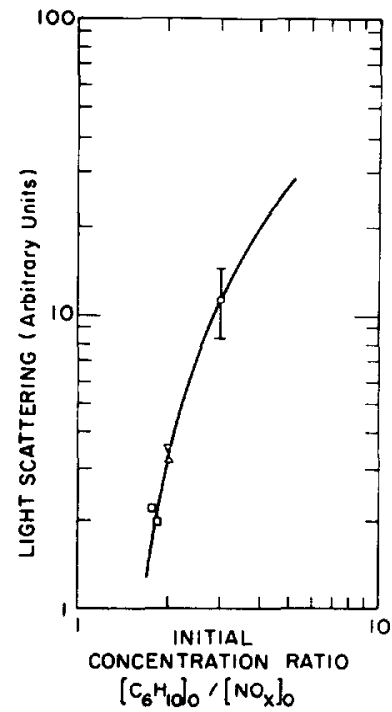

Fig. 7. Light scattering from particles produced in cyclohexene-nitrogen oxides-air mixtures. $\triangle$ Groblicki and Nebel (1971); $\nabla$ Prager et al. (1960); $\phi$ Renzetti and Doyle (1960); $\square$ Stevenson et at. (1965). 
is increased from 40 to $400 \mathrm{~cm}^{-3}$; the light scattering from 3 to 30). Second, the light scattering measurements support the present observation that few particles are produced when the concentration ratio is below 2.4 .

Recently, Miller and Levy (1976) reported photochemical particle formation in auto exhaust air mixtures. The mixture contained several different hydrocarbons and, therefore, their results cannot be compared directly to those presented in this paper.

Most of the data obtained in our laboratory were taken at $50 \%$ relative humidity. In order to evaluate the effect of relative humidity on the number of nuclei and particles, some measurements were also made at $100 \%$ relative humidity. The data obtained for $100 \%$ humidity are represented by dark circles in Figs. 4 and 6. The results in Figs. 4 and 6 indicate that a change in relative humidity from 50 to $100 \%$ did not affect significantly the number of nuclei and particles in the mixture.

The foregoing results demonstrate the usefulness of the dimensionless parameters given in Figs. 4 and 6 in correlating ozone, nuclei, and particle data generated by photochemical reactions. The use of these dimensionless parameters should also enable comparisons between nuclei and particle data obtained in different smog chamber experiments, in a manner similar to that done for ozone by Shen et al. (1976). When sufficient test results become available, the data correlated according to these parameters could conceivably be used to predict the maximum numbers of nuclei and particles forming in given hydrocarbon-nitrogen dioxide - air mixtures.

Acknowledgement--The authors thank J. S. Wallace for his help in obtaining the data at $100 \%$ relative humidity, and for his helpful comments on the manuscript.

\section{REFERENCES}

Groblicki, P. J., Nebel, G. J. (1971) The Photochemical Formation of Aerosols in Urban Atmospheres, in Chemical Reactions in Urhan Atmospheres, Tuesday, C. S. F.d., 241-264, Elsevier, New York.

Miller, D. F., Levy, A. (1976), "Exhaust Hydrocarbon Relationships with Photochemical Aerosol Formation," J. Air Pollut. Control Assoc. 26, 778-782.

Prager, M. J., Stephens, E. R., Scott, W. E. (1960), "Aerosol Formation from Gaseous Air Pollutants," Ind. Eng. Chem. 52, 521-524.

Renzetti, N. A., Doyle, G. J. (1960), "Photochemical Aerosol Formation in Sulfur Dioxide-Hydrocarbon Systems," Int. J. Air Poll. 2. 327-345.

Shen, C. H., Springer, G. S. (1975), Ozone and Particulate Formation in Photochemical Reactions. Fluid Dynamics Laboratory, Publication No. 75-1, Department of Mechanical Engineering, University of Michigan, Ann Arbor, Michigan.

Shen, C. H., Springer, G. S. (1976), "Photochemical Particulate Formation in Sulfur Dioxide-Air Mixtures," Atmospheric Environment 10, 235-239.

Shen, C. H., Springer, G. S., Stedman, D. H. (1977), "Photochemical Ozone Formation in Cyclohexene-Nitrogen Dioxide-Air Mixtures," Environ. Sci. Technol. 11, 151-158.

Stevenson, H. J. R., Sanderson, D. E., Altshuller, A. P. (1965), "Formation of Photochemical Aerosols," Int. J. Air Wat. Poll. 9, 367-375. 